\title{
Cigarette Smoke Induces Apoptosis by Activation of Caspase-3 in Isolated Fetal Rat Lung Type II Alveolar Epithelial Cells in Vitro
}

\author{
Asra Ahmed ${ }^{1}$, James A. Thliveris ${ }^{2}$, Anthony Shaw ${ }^{1,3}$, Michael Sowa ${ }^{1,3}$, \\ James Gilchrist ${ }^{1}$, J. Elliott Scott ${ }^{1,2,4^{*}}$ \\ ${ }^{1}$ Departments of Oral Biology, Manitoba Institute for Child Health, University of Manitoba, Winnipeg, Canada \\ ${ }^{2}$ Human Anatomy and Cell Science, Manitoba Institute for Child Health, University of Manitoba, Winnipeg, Canada \\ ${ }^{3}$ Manitoba Institute for Child Health, The National Research Council Biodiagnostics Institute, \\ University of Manitoba, Winnipeg, Canada \\ ${ }^{4}$ The Biology of Breathing Group, Manitoba Institute for Child Health, University of Manitoba, Winnipeg, Canada \\ Email: *mailto:jscott@cc.umanitoba.ca
}

Received December 6, 2012; revised January 8, 2013; accepted January 20, 2013

\begin{abstract}
Smoking during pregnancy is a major source of fetal exposure to numerous harmful agents present in tobacco smoke. Lung development involves complex biochemical processes resulting in dramatic changes which continue even after birth. In addition to type I cells which form the blood-air barrier, type II alveolar epithelial (AE) cells have important and diverse functions related to immunological protection and stabilization of the alveolus through synthesis and secretion of the pulmonary surfactant. Apoptosis or programmed cells death is an important physiological process during lung embryogenesis and for the proper maintenance of homeostasis. Caspases are proteases that play important roles in regulating apoptosis. Caspase-3 is the key executioner caspase in the cascade of events leading to cell death by apoptosis. We explored the hypothesis that cigarette smoke extract (CSE) induces apoptosis in fetal rat lung type II AE cells by activation of caspase-3. To analyze these factors, isolated fetal rat lung type II AE cells were used. The cells were exposed to different concentrations of CSE $(5 \%, 10 \%$ or $15 \%)(\mathrm{v} / \mathrm{v})$ for $60 \mathrm{~min}$. The results of the present study showed that CSE induced apoptosis in fetal rat lung type II AE cells with a significant increase $(p<0.05)$ in caspase-3 activity and decrease in cell proliferation at CSE concentrations of $10 \%$ and $15 \%(\mathrm{v} / \mathrm{v})$. These observations indicate that cigarette smoke extract induces apoptosis by activation of caspase- 3 in fetal rat lung type II AE cells in a dose-dependent manner and may potentially alter the regulated development of the lung and the appearance of the surfactant-producing type II alveolar cells which are critical for the establishment of adequate gas exchange at birth.
\end{abstract}

Keywords: Cigarette Smoke Toxicity; Fetal Rat Lung Type II Alveolar Cells; Apoptosis; Protease; Caspase-3; Lung Development; Developmental Toxicity; Maternal Smoking

\section{Introduction}

Cigarette smoke contains more than 4000 chemicals including addictive and carcinogenic agents which significantly contribute to the progression of pulmonary disease. Cigarette smoking during pregnancy is a major source of prenatal exposure to harmful agents in tobacco smoke to the developing fetus. Despite the consequences, 30\% $40 \%$ of women smoke during pregnancy worldwide [1]. Exposure of tobacco smoke and second-hand smoke in utero has been associated with neonatal mortality, growth retardation [2], low birth weight, sudden infant death syndrome, preterm delivery and higher incidence of stillbirth [3].

\footnotetext{
"Corresponding author.
}

The respiratory system is one of the most structurally complex and critical systems of the body and its development begins during the fifth week of gestation [4]. The adult lungs are comprised of forty different types of cells. Among these the major cell types include fibroblasts, type I alveolar epithelial (AE) cells, type II alveolar epithelial (AE) cells and macrophages. The alveolar epithelium is formed of type I AE cells and type II AE cells. The type II AE cells cover only $\sim 5 \%$ of the total alveolar epithelial surface comprising $16 \%$ of the total lung cell population [5]. They are interspersed between type I AE cells and are thought to be progenitor cells of type I AE cells during lung development [6] and injury [7]. Furthermore, these cells release growth factors which help regulate cell growth following injury. Type II AE 
cells are characterized morphologically by the presence of large intracellular concentric membrane bounded storage units of surfactant, known as lamellar bodies (LB). The major functions of type II AE cells include synthesis, secretion and regulation of surfactant which essential for normal biophysical and immuno-modulatory functions of the lung. It is the first site of defense against inhaled components of air such as cigarette smoke (CS). There is preliminary evidence that intrauterine fetal smoke exposure alters lung development [3] and the infants born to mothers who smoke during pregnancy are small for their gestational age.

Typically, in normal lung development apoptosis or programmed cell death plays an important role to maintain equilibrium between cell death and cell proliferation. A defect in apoptotic processes during embryogenesis may lead to developmental abnormalities [8]. Apoptosis is an irreversible, timely regulated form of cell death essential for proper maintenance of homeostasis, during embryogenesis and for functional regulation of the immune system [9]. Cells undergoing apoptosis show characteristic well defined morphologic changes differentiating it from necrosis. Apoptotic stimuli can be initiated extracellularly or intracellularly. The process of apoptosis is not associated with any inflammatory response as the cellular contents of dying cells are not released in the surrounding interstitial tissues. Furthermore, apoptosis is a complex, multi-step process which involves biochemical events including activation of an intracellular proteolytic caspase cascade, which is important in the regulation and execution of apoptotic cell death. Knowledge of the importance of caspases in apoptosis has been made possible through studies on knockout animals deficient of particular caspases which confirmed profound defects in apoptosis [10]. Moreover, studies involving use of inhibitors of caspases which effectively inhibit apoptosis also help understand the important role of caspase activation in apoptosis [11].

Caspases, are proteases which belong to the family of cysteine-aspartic acid endopeptidases. Caspases are primarily localized in the cytoplasm and are synthesized as inactive enzyme precursors or zymogens [12]. Recent studies report the existence of caspases in the mitochondrial intra-membrane space (pro-caspase-2, $-3,-8$ and -9), endoplasmic reticulum (pro-caspase-12) nucleus and Golgi apparatus (pro-caspase-2) [13].

Caspases are broadly classified into two groups; one which is thought to play a central role in apoptosis (caspases-2, -3, -6, -7, -8, -9, -10, and -12) and a second group which is primarily involved in cytokine processing during inflammation (caspases-1, -4, and -5) [14].

Of these enzymes caspase- 3 also known as CPP32, YAMA or apopain is considered as the major executioners of apoptosis. It is the first of all the effector caspases to be activated for amplifying downstream apoptotic processes. Caspase- 3 can be activated through caspase- 8 and caspase- 9 by extrinsic or intrinsic signaling, respectively [15], suggesting, that the apoptotic signals from either extrinsic or intrinsic pathways converge for activetion of caspase-3. Activated caspase- 3 has been reported to contribute mainly to the morphologic changes in apoptotic cells including membrane blebbing, chromatin condensation and DNA fragmentation [10] and has been reported in developing lung in the pseudoglandular branching morphogenesis phase [16].

The aim of the present study was to examine the effect of cigarette smoke extract on fetal lung type II AE cells. We hypothesized that cigarette smoke extract induces apoptosis in type II AE cells through activation of caspase-3.

\section{Materials and Methods}

\subsection{Preparation of Cigarette Smoke Extract}

Cigarette smoke extract (CSE) was prepared according to method designed by Janoff and Carp [17]. Unfiltered research cigarettes from University of Kentucky, each containing $2.45 \mathrm{mg}$ nicotine/cigarette [18] were used. Cigarette smoke was drawn from each cigarette into a 50 $\mathrm{ml}$ syringe for two seconds maintaining a gap of $20 \mathrm{sec}-$ onds between each draw with the syringe and bubbled through $50 \mathrm{ml}$ of minimum essential medium (MEM) at room temperature. This cycle was repeated until the end of the cigarette. $50 \mathrm{ml}$ of fresh MEM was used for the next cigarette. The resulting smoke extracted MEM was considered to be $100 \%$ CSE. It was filtered using 0.22 $\mu \mathrm{m}$ pore filters (Millipore) to sterile and stored at $-80^{\circ} \mathrm{C}$. Further dilutions $(5 \%, 10 \%$ and $15 \%)$ were made in serum-free media containing antibiotics and fungizone. Before treating cells with conditioned media, the $\mathrm{pH}$ was adjusted to 7.2 .

\subsection{Isolation and Culture of Type II AE Cells}

Use of animals was approved according to the Canadian Council on Animal Care guidelines. Timed pregnant Sprague-Dawley rats purchased from Central Animal Services, University of Manitoba were used to isolate fetal lung type II alveolar cells. Rats were euthanized with an intra-peritoneal injection of $1 \mathrm{ml}$ Euthanyl $(240 \mathrm{mg} / \mathrm{ml}$ sodium pentobarbital) on gestational day 21 (day 22.5 is term gestation). Fetuses were removed by hysterotomy, decapitated and placed in cold, sterile Hanks Balanced Salt Solution (HBSS, Gibco, ON Canada). Lungs were dissected from fetuses by making an incision in the midsternal region. Lungs were minced using a Sorval tissue chopper (Sorval Instruments, Newton, CT) in a laminar flow hood. The minced lung tissue was dissociated by incubating with trypsin-EDTA $(0.05 \% / 0.02 \%)$ in HBSS at $37^{\circ} \mathrm{C}$ for 45 minutes in a water-jacketed trypsinization flask which was placed on a magnetic stirrer. Minimal 
essential medium (MEM) (Gibco, ON Canada) containing $10 \%$ of newborn calf serum (NCS), antibiotics/antimycotic (1\%) and fungizone (1\%) (Gibco, ON Canada) was added to stop further enzymatic disaggregating. The dissociated cells were filtered through three layers of 150 $\mu \mathrm{m}$ Nitex gauze to remove tissue fragments and centrifuged for $10 \mathrm{~min}$ at $1000 \mathrm{rpm}$ at $4^{\circ} \mathrm{C}$. The cell pellet was re-suspended in $10 \mathrm{ml}$ of MEM/NCS and cells were plated in five $75 \mathrm{~cm}^{2}$ tissue culture flasks in a humidified incubator $\left(95 \%\right.$ air $/ 5 \% \mathrm{CO}_{2}$ and $\left.37^{\circ} \mathrm{C}\right)$ and allowed to adhere for one hour. Fibroblasts have the ability to attach faster when compared to type II cells [19]. Fetal type II AE cells were separated by differential adherence [20]. After one hour of incubation and adherence of fibroblasts, the media with unattached cells was collected. Cells were counted and re-plated at a density of $1.5 \times 10^{5}$ cells/flask. Type II cells were cultured in media supplemented with $10 \%$ carbon stripped serum (sNCS) in MEM and $1 \%$ antibiotics, antimycotic, fungizone and cultured in a humidified incubator $\left(95 \%\right.$ air $/ 5 \% \mathrm{CO}_{2}$ and $\left.37^{\circ} \mathrm{C}\right)$. Medium was changed after 24 hours and 48 hours thereafter.

\subsection{Detection of Caspase-3 Activity in Adherent Cells Exposed to CSE}

Once the cultures reached $70 \%-80 \%$ confluence, they were washed twice with HBSS and treated for 60 minutes with different concentrations of CSE diluted in serum-free media. Cells were washed three times with HBSS to ensure complete removal of traces of CSE. Caspase-3 activation in cells was determined using the caspase-3 fluorometric assay kit, purchased from BioVision (MountainView, CA). The cells were lysed using the lysis buffer provided ( $50 \mathrm{ul}$ per well), incubated on ice for ten minutes, and incubated with $5 \mathrm{ul}$ of fluorogenic substrate $1 \mathrm{mM}$ DEVD-AFC (caspase- 3 cleaves this substrate) in a reaction buffer (containing $10 \mathrm{mM}$ DTT) in the incubator at $37^{\circ} \mathrm{C}$ for two hours. The enzymatic activity was measured using a fluorescence microplate reader with $400 \mathrm{~nm}$ excitation and $505 \mathrm{~nm}$ emission filters. Caspase-3 cleaves the AFC substrate (Figure 1) and releases a fluorogenic signal; this signal is directly proportional to the level of enzymatic activity of caspase- 3 in cells. Caspase-3 activity was calculated in samples of cells exposed to CSE and compared to untreated controls.

\subsection{Effect of N-benzyloxycarbonyl-Val-Ala-Asp- fluoromethylketone (Z-VAD-fmk)}

$\mathrm{Z}-\mathrm{VAD}$-fmk, is a broad spectrum caspase inhibitor which was used in the present study to examine the involvement of caspases in cell death due to CSE. The cells were incubated with $80 \mathrm{mM} \mathrm{Z-VAD-fmk} \mathrm{in} \mathrm{serum-free} \mathrm{medium}$ at the time of exposure of cells to CSE for $60 \mathrm{~min}$. After which the cells were washed and the caspase-3 activity was measured as described above.

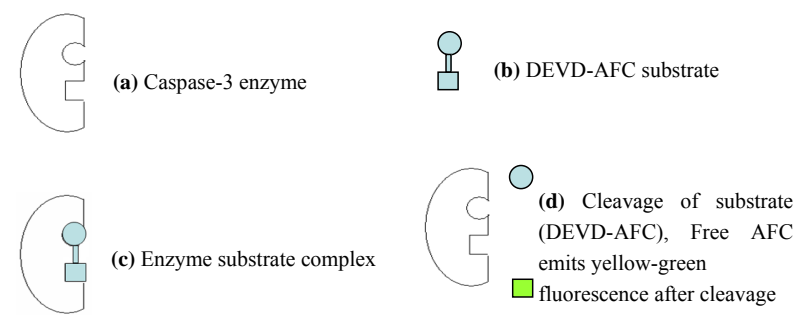

Figure 1. Schematic illustration of DEVD dependent detection of caspase- 3 activity. Activation of caspase- 3 is a key event of apoptosis. Caspase-3 fluorometric assay kit (BioVision, Mountain View) is based on detection of cleavage of substrate DEVD-AFC by caspase-3. DEVD-AFC substrate emits blue light $(400 \mathrm{~nm})$. After cleavage of the substrate by caspase-3, free AFC emits yellow-green fluorescence (505 $\mathrm{nm}$ ). The amount of fluorescence can be quantified using a fluorometric plate reader.

\subsection{Determination of Cellular Viability}

The cells were treated with different concentrations of CSE as described above. After incubation with different concentrations of CSE the cells were washed with HBSS three times to ensure complete removal of CSE and further incubated with MTT solution for three hours. The MTT-based cell proliferation assay (Sigma Aldrich, St. Louis, MO, USA), is a calorimetric assay used to measure the ability of mitochondrial dehydrogenase of viable cells to reduce the key component, MTT or 3-[4,5-dimethylthiazol-2-yl]-2,5diphenyl tetrazolium bromide, a yellow tetrazole to insoluble purple formazan crystals. Viable cells cleave the tetrazolium ring of MTT and the yellow water-soluble dye is converted to insoluble purple crystals of formazan. After three hours of incubation with MTT solution the crystals were dissolved in MTT solvent. The plates were read spectrophotometrically at an absorbance of $570 \mathrm{~nm}$. The intensity of purple color in the solution is indicative of the number of living cells.

\subsection{Western Blot Analysis}

At the end of treatment with CSE, cells were washed three times with HBSS to ensure complete removal of any remnants of CSE. The cells were lysed by adding one $\mathrm{ml}$ of 2XRIPA buffer with protease inhibitor tablet [20 mM Tris-HCL pH 7.6, $316 \mathrm{mM} \mathrm{NaCl}, 2$ mM EDTA, $2 \%$ triton $\times 100,0.2 \%$ SDS, $2 \%$ sodium deoxycholate, 1 mM PMSF, $1 \mathrm{mM} \mathrm{Na} \mathrm{VO}_{4}, 1$ protease inhibitor tablet] and stored at -80 until processed. Protein samples were quantified using Bradford protein determination method. Equal amounts of protein extracts were subjected to electrophoresis on $12 \%$ sodium dodecyl sulfate-polyacrylamide pre-cast gels (BIO-RAD, Mississauga, ON), electrophoresed at $180 \mathrm{~V}$ and later transferred to nitrocellulose membranes. The blots were probed with primary antibody (rabbit polyclonal) purchased from Santa Cruz Biotechnology (Santa Cruz, CA, USA) and diluted (1:500) 
in blocking buffer overnight at $4^{\circ} \mathrm{C}$. This antibody recognizes the $\mathrm{p} 17$ fragment of an activated form of caspase-3 (Santa Cruz, CA, USA). After three washes with TBS-T blots were incubated with goat anti rabbit IgG-HRP secondary antibody (Santa Cruz, CA, USA) at a dilution of 1:1000 in blocking buffer for two hours at room temperature and detected using ECL-plus (GE Healthcare, NJ, USA) and exposed on Kodak films. The densities of cleaved caspase-3 bands were quantified using Quantiscan.

\subsection{Subcellular Localization of Caspase-3 Using Immunofluorescence}

Subcellular localization of caspase- 3 in cells exposed to CSE was observed using immunofluorescence microcopy. Cells were plated in four well glass chamber slides and left overnight in incubator at $37^{\circ} \mathrm{C}$ for attachment on glass slides. The cells were exposed to $10 \%$ or $15 \%$ CSE in serum-free medium and left in the incubator for 60 min at $37^{\circ} \mathrm{C}$. After which the cells were washed with PBS three times and fixed with cold methanol $\left(-10^{\circ} \mathrm{C}\right)$ for $5 \mathrm{~min}$ followed by three washes with PBS, suction was used between each wash to completely remove the reagents. The cells were blocked in $2 \% \mathrm{BSA} / 1 \times \mathrm{PBS}$ for one hour in a humidified chamber. The primary antibody rabbit-polyclonal $\mathrm{IgG}$, which recognizes active caspase-3 was diluted (1:800 dilution) in blocking solution was incubated overnight at $4{ }^{\circ} \mathrm{C}$ with the cells in a humidified chamber. After four washes with PBS cells were incubated with secondary anti body, FITC conjugated donkey anti-rabbit IgG which recognizes rabbit IgG (Santa Cruz). The secondary antibody was diluted $1: 80$ in $2 \% \mathrm{BSA} / 1 \mathrm{x}$ PBS and cells were incubated in a humidified chamber for one hour in the dark. All steps after this were done in the dark. After four washes with PBS the cells were stained with Hoescht 33,342 (1:1000) for 15 seconds. Following washing the slides were air-dried and mounted with coverslips using $40 \mu \mathrm{l}$ Prolong Anti-fade Gold. The slides were observed under an inverted fluorescence microscope (BX61 Olympus microscope) using Image Pro. Software.

\subsection{Statistical Analysis}

Statistical differences between group means were carried out using post hoc Duncan's Multiple Range Test [21]. A value of $p<0.05$ was considered for statistically significant differences between the treated and untreated groups.

\section{Results}

\subsection{Detection of Caspase-3 Activity in Adherent Cells Exposed to CSE}

Exposure to CSE at concentrations of $10 \%$ or $15 \%(\mathrm{v} / \mathrm{v})$ produced significantly elevated activity $(p<0.05)$ of caspase-3 compared to the non-exposed cells (Figure 2). No significant differences were observed in the caspase-3 activity in cells exposed to $5 \%$ CSE compared to the nonexposed cells.

\subsection{Effect of N-benzyloxycarbonyl-Val-Ala-Asp- fluoromethylketone (Z-VAD-fmk)}

For further confirmation, apoptotic cell death was evaluated after treatment with Z-VAD-fmk (Figure 3), a broad spectrum caspase inhibitor. Isolated fetal rat lung type II AE cells were exposed to different concentrations of CSE $(5 \%, 10 \%$ or $15 \%)$ and Z-VAD-fmk (80 uM concentration) was added for 60 minutes. Caspase-3 activity in was measured using the fluorometric assay kit at 400 $\mathrm{nm}$ excitation and $505 \mathrm{~nm}$ emission. Z-VAD-fmk inhibited caspase- 3 activity in all samples exposed to CSE when compared to the caspase-3 activity in cells without Z-VAD-fmk $(p<0.05)$.

\subsection{Determination of Cell Viability}

MTT formazan assay (Figure 4) was used to measure cellular mitochondrial dehydrogenase activity within a cell and is based on the conversion of mitochondrial-dependent MTT, (3-(4,5-dimethylthiazol-2-yl)-2,5-diphenyltetrazolium bromide) to purple formazan crystals. There was a significant decrease $(p<0.05)$ in the mitochondrial activity of cells exposed to $10 \%$ or $15 \%$ CSE compared to the cells not exposed to CSE.

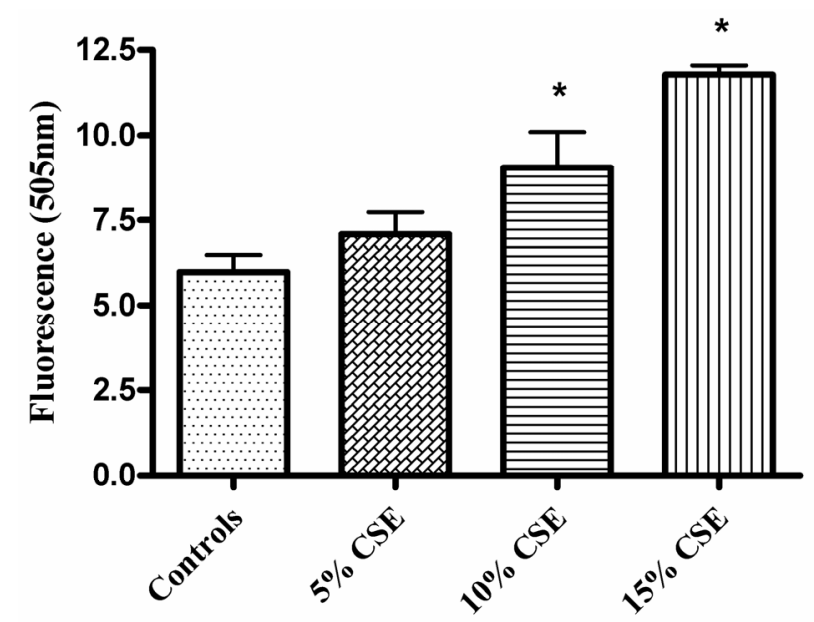

Figure 2. Effect of CSE on caspase-3 activity in isolated fetal rat lung type II alveolar epithelial cells. Fluorometric assay to assess the activity of caspase- 3 in fetal rat lung type II AE cells exposed to different concentrations of CSE (5\%, $10 \%$ or $15 \%)(v / v)$ for 60 minutes in $37^{\circ} \mathrm{C}$ incubator. Cells not exposed to CSE were considered as controls. Each bar represents the mean $\pm S E M$ of three experiments of 16 samples in each. ${ }^{*}(p<0.05)$ significantly different from the corresponding controls. 


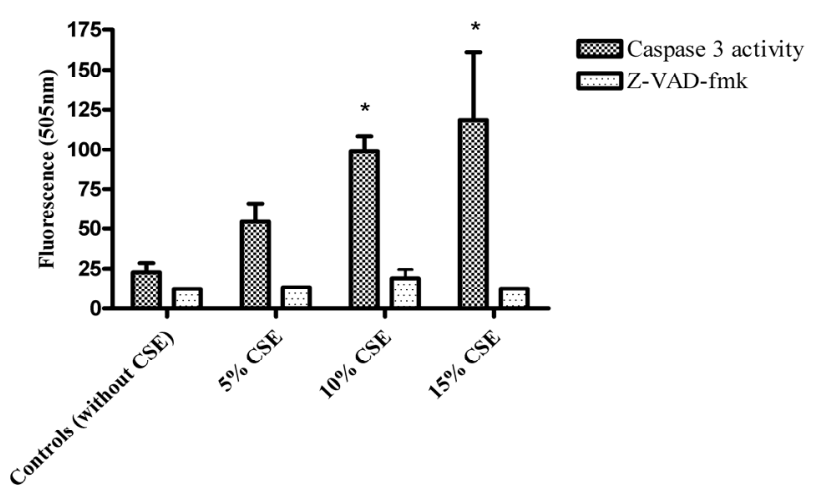

Figure 3. Effect of Z-VAD-fmk and caspase-3 activity in isolated fetal rat lung type II AE cells exposed to CSE. Caspase- 3 activity and effect of Z-VAD-fmk was measured using caspase-3 fluorometric assay in fetal rat lung type II cells exposed to $5 \%, 10 \%$ or $15 \%(v / v)$ CSE for 60 minutes. Each bar represents the mean of \pm SEM of three experiments of 16 samples each. "significantly $(p<0.05)$ different from the corresponding controls.

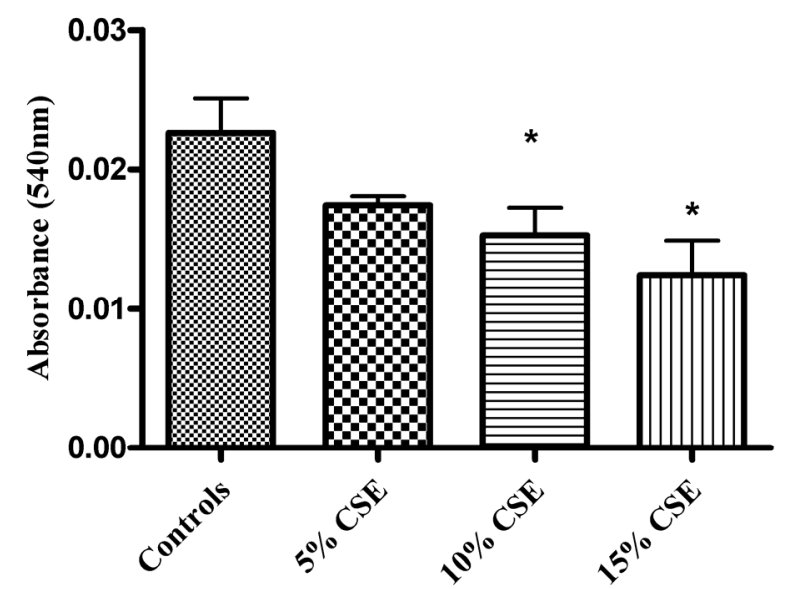

Figure 4. Effect of CSE on cell viability in isolated fetal rat lung type II AE cells. MTT activity was measured in fetal rat lung type II AE cells exposed to different concentrations of $\operatorname{CSE}(5 \%, 10 \%$ or $15 \%)(v / v)$ for 60 minutes. Cells not exposed to CSE were considered as controls. Level of absorbance was measured at $540 \mathrm{~nm}$. Each bar represents the mean \pm SEM of three experiments of 16 samples in each. ${ }^{*}(p$ $<0.05)$ significantly different from the corresponding controls.

\subsection{Western Blot Analysis}

The expression of caspase-3 in isolated fetal rat type II AE cells was analyzed by SDS-PAGE (Figure 5). Lysates of cells not exposed to CSE were considered as controls. The results of fetal rat lung type II AE cells shows that an antibody specific for detecting active form of caspase- 3 bond to the protein band with relative molecular mass of $17 \mathrm{kDa}$, which is the accepted molecular mass of active caspase-3 [22]. The densitometric analysis of caspase-3 expression in these cells was significantly in-

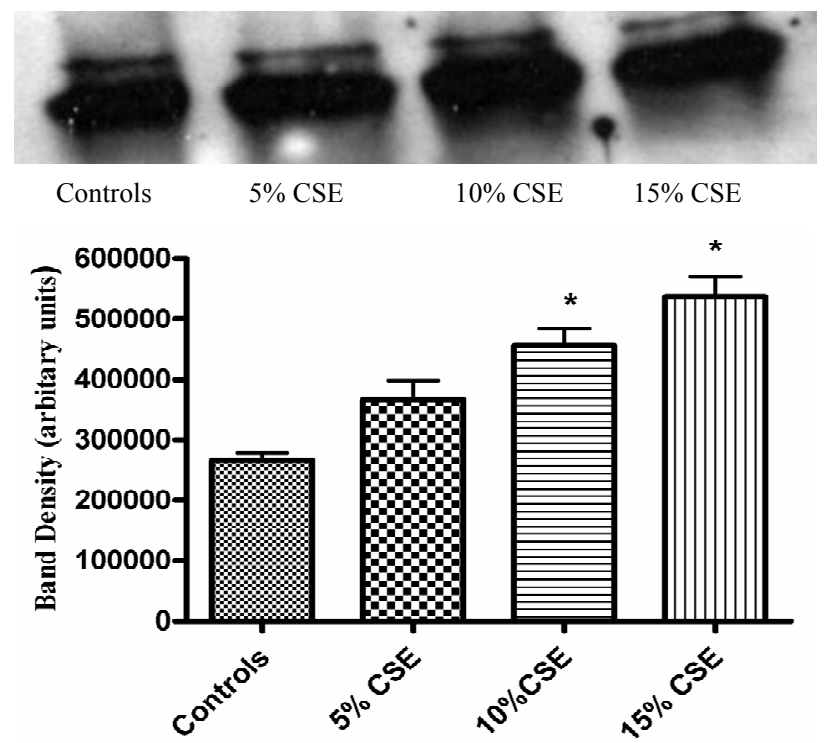

Figure 5. Effect of CSE on caspase-3 expression in fetal rat lung type II AE cells. (A) Representative Western bolt showing caspase- 3 expression in fetal rat lung type II AE cells treated with $5 \%, 10 \%$ or $15 \%$ (v/v) CSE for 60 minutes. Cells not exposed to CSE were considered as controls. (B) Densitometric analysis of band intensity shows each bar representing the mean \pm SEM of three experiments. ${ }^{*}(p<$ 0.05) significantly different from the corresponding controls.

creased $(p<0.05)$ in the samples exposed to $10 \%$ or $15 \%$ CSE.

\subsection{Sub-Cellular Localization of Caspase-3 Using Immunofluorescence}

The sub-cellular localization of caspase-3 expressed in isolated fetal rat lung type II AE cells after exposure to CSE was determined by immunofluorescence using fluorescence microscopy (Figure 6). Controls consisted of samples in which the primary antibody against caspase -3 was omitted. No green fluorescence was observed in these samples. Caspase-3 activity was localized largely within the cytoplasm of the isolated type II cells. A gradient of expression appeared to be present in that relatively little fluorescence was present at the periphery of the cell immediately adjacent to the cell membrane but fluorescence increased towards the nucleus. Caspase- 3 activity appeared to be the most intense near the nuclear membrane.

\section{Discussion}

In the present study we demonstrated that CSE induces apoptosis through activation of caspase-3 in isolated fetal rat lung type II AE cells in vitro. As previously reported type II AE cells are regarded as the "defenders" of the alveolus due to their diverse functions [22]. Any damage 
FITC
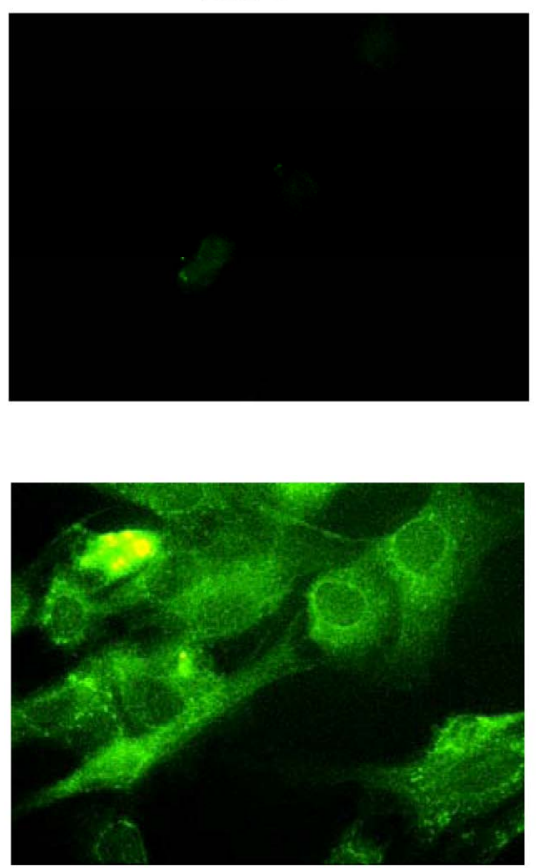

DAPI

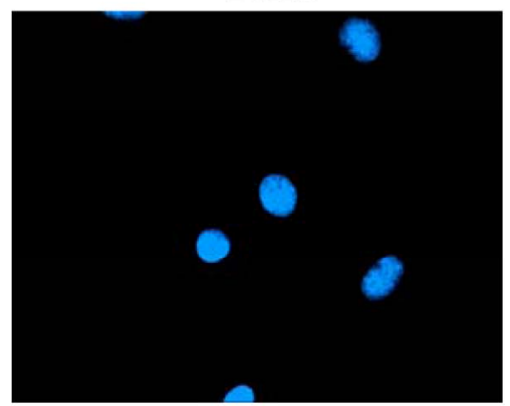

(a)

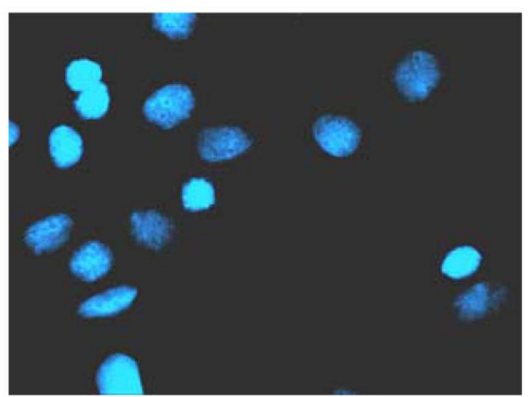

(b)
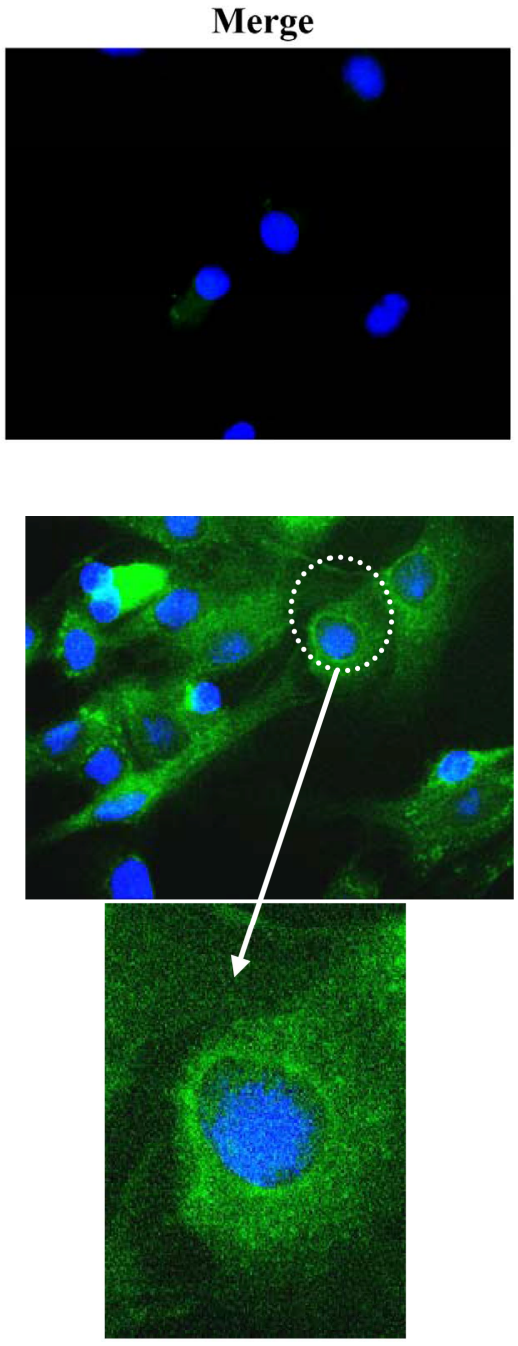

(c)

Figure 6. Immunofluorescence staining for detection of caspase-3 expression in isolated fetal rat lung type II AE cells. Isolated fetal rat lung type II AE cells were exposed to CSE (15\% v/v). Immunofluorescence was performed using caspase-3 rabbit polyclonal IGg antibody. Caspase-3 was visualized using donkey anti-rabbit IGg-FITC (green fluorescence) and counter stained with Hoescht 33,342 (nuclear staining-blue). Image (a) shows controls (without primary anti-body); Image (b) shows expression of caspase-3 (green) primarily localized in the cytoplasm; (c) Shows an enlarged image of a positive stained cell. FITC—Fluorescein isothiocyanate; DAPI-4,6-diamidino-2-phenylindole; Merge-merged image of FITC and DAPI.

to type II AE cells may result in 1) alveolar collapse due to decreased surfactant production; 2) defects in remodeling of alveolar structure due to decrease in cytokines and growth factors; 3 ) increase in epithelial permeability [23]. It has been reported that exposure of type II AE cells to CS leads to oxidative damage of the respiratory epithelium and induces DNA damage [24], which is an important feature of cellular apoptotic death. Cigarette smoke can be divided into two phases, the tar phase/particulate phase and gas phase, both of which are rich sources of free radicals [25]. The tar phase contains free radicals which are stable and are retained on the filter when a cigarette is smoked. In contrast, the gas smoke phase contains less stable free radicals, which are more reactive and can penetrate through the filter [26]. The gas phase can be further divided into mainstream smoke and side stream smoke. The mainstream smoke is directly inhaled through the cigarette and contains $8 \%$ tar and $92 \%$ gaseous components [26]. Side stream smoke is the smoke emitted from the burning end of the cigarette. Environmental smoke is a combination of side stream and exhaled mainstream smoke. In the present study CSE was prepared using unfiltered research cigarettes, which included both phases of smoke components. Water soluble components remain in the media during exposure to cells. The solution which is considered as $100 \%$ CSE 
was further diluted for all assays. Previous studies in our laboratory have found these high levels of CSE to be cytotoxic. Fetal growth and development is influenced by intrauterine environment and governed by physical, environmental and hormonal factors [27]. This environment is carefully regulated and consists of various hormones including vascular endothelial growth factor (VEGF) and fibroblast growth factor (FGF) [27]. Both of these hormones contribute to type II alveolar cell differentiation as well as production and secretion of surfactant phospholipids and proteins [27]. Moreover, alterations in the intra-uterine environment due to exposure to cigarette smoke may affect lung function [28]. It may result in decreased alveolarization [1] and altered formation of pulmonary surfactant, which is the first line of defense against pollutants and critical for proper lung expansion at birth [29]. Furthermore, intra-uterine smoke exposure affects lung development adversely with a significant reduction in lung growth [30], with an increased risk of asthma in childhood [31]. The mechanisms underlying the pulmonary effects due to CSE exposure are still not clearly elucidated. It is widely accepted that apoptosis or programmed cell death plays an important role during all stages of lung development (pre and post-natal) and repair of lungs following injury [16,32]. The deregulation of apoptosis may lead to development of lung disease. Hyperoxia which inhibits distal airway branching within fetal mouse pulmonary mesenchyme and is associated with bronchopulmonary dysplagia activates caspase-3 [33]. In addition acute respiratory syndrome induced by coronavirus results in apoptotic activation through a caspasedependent mechanism [34]. Interestingly differential apoptosis in type II alveolar cells and interstitial fibroblasts may be involved with pulmonary fibrosis and post injury inadequate re-epithelialization [35].

Caspases, which are responsible for initiation and execution of apoptosis, upon receiving apoptotic stimuli become activated and the process of cell death is carried out through proteolytic cleavage. Caspase- 3 is the central caspase in the caspase cascade that mediates the execution of the apoptotic process of cell death [36]; however, little is known about the ability of CSE to activate caspase- 3 in fetal lung cells. Both the intrinsic and extrinsic pathways of apoptosis converge to the activation of caspase-3 [37]. Once activated caspase-3 cleaves nuclear protein substrates leading to DNA fragmentation [38] eventually leading to cell death.

In conclusion, our study showed that CSE induced an increase in apoptosis and a reduction of cell proliferation in fetal rat lung type II AE cells following exposure to CSE. As both these processes are critical for maturation and acquisition of the adequate pulmonary surface of the lung during development, observations that CSE disrupts this program can account for the onset of respiratory inadequacies when the fetus is exposed in utero to chemicals found in cigarette smoke. Since type II AE cells secrete surfactant which is the first line of defense against pathogens and toxic substances, any damage to these cells could mean an overall deterioration of lung function. To our knowledge this is the first study which demonstrates the increase in apoptosis through activation of caspase-3 and decrease in cell growth in fetal lung type II AE cells exposed to CS in vitro. However, the underlying cellular mechanisms and signaling pathways that explain the theory behind these changes remain to be resolved. Further studies are required to investigate the specific factors inducing apoptosis in tobacco exposed fetal lungs.

\section{Acknowledgements}

This work was supported by the Natural Science and Engineering Research Council of Canada (NSERC) and the Manitoba Institute for Child Health.

\section{REFERENCES}

[1] J. Stocks and C. Dezateux, "The Effect of Parental Smoking on Lung Function and Development during Infancy," Respirology, Vol. 8, No. 3, 2003, pp. 266-285. doi:10.1046/j.1440-1843.2003.00478.x

[2] J. M. Roquer, J. Figueras, F. Botet and R. Jimenez, "Influence on Fetal Growth of Exposure to Tobacco Smoke during Pregnancy," Acta Paediatrica, Vol. 84, No. 2, 1995 , pp. $118-121$. doi:10.1111/j.1651-2227.1995.tb13592.x

[3] J. R. DiFranza, C. A. Aligne and M. Weitzman, "Prenatal and Postnatal Environmental Tobacco Smoke Exposure and Children's Health," Pediatrics, Vol. 113, No. S4, 2004, pp. 1007-1015.

[4] M. Selman and A. Pardo, "Role of Epithelial Cells in Idiopathic Pulmonary Fibrosis: From Innocent Targets to Serial Killers," Proceedings of American Thoracic Society, Vol. 3, No. 4, 2006, pp. 364-372. doi:10.1513/pats.200601-003TK

[5] D. Wang, D. L. Haviland, A. R. Burns, E. Zsigmond and R. A. Wetsel, "A Pure Population of Lung Alveolar Epithelial Type II Cells Derived from Human Embryonic Stem Cells," Proceedings of the National Academy of Sciencesof United States of America, Vol. 104, No. 11, 2007, pp. 4449-4454. doi:10.1073/pnas.0700052104

[6] A. E. Bishop, "Pulmonary Epithelial Stem Cells," Cell Proliferation, Vol. 37, No. 1, 2004, pp. 89-96. doi:10.1111/j.1365-2184.2004.00302.x

[7] Z. Borok and E. D. Crandall, "More Life for a 'Terminal' Cell," American Journal of Physiology-Lung Cellular and Molecular Physiology, Vol. 297, No. 6, 2009, pp. L1042-L1044. doi:10.1152/ajplung.00355.2009

[8] C. Haanen and I. Vermes, "Apoptosis: Programmed Cell Death in Fetal Development," European Journal of Obstetrics \& Gynecology and Reproductive Biology, Vol. 64, 
No. 1, 1996, pp. 129-133. doi:10.1016/0301-2115(95)02261-9

[9] S. Elmore, "Apoptosis: A Review of Programmed Cell Death," Toxicologic Pathology, Vol. 35, No. 4, 2007, pp. 495-516. doi:10.1080/01926230701320337

[10] C. Kohler, S. Orrenius and B. Zhivotovsky, "Evaluation of Caspase Activity in Apoptotic Cells," Journal of Immunological Methods, Vol. 265, No. 1-2, 2002, pp. 97110. doi:10.1016/S0022-1759(02)00073-X

[11] P. G. Ekert, J. Silke and D. L. Vaux, "Caspase Inhibitors," Cell Death \& Differentiation, Vol. 6, No. 11, 1999, pp. 1081-1086. doi:10.1038/sj.cdd.4400594

[12] D. W. Nicholson and N. A. Thornberry, "Caspases: Killer Proteases," Trends in Biochemical Sciences, Vol. 22, No. 8, 1997, pp. 299-306. doi:10.1016/S0968-0004(97)01085-2

[13] D. Chandra and D. G. Tang, "Mitochondrially Localized Active Caspase-9 and Caspase-3 Result Mostly from Translocation from the Cytosol and Partly from CaspaseMediated Activation in the Organelle. Lack of Evidence for Apaf-1-Mediated Procaspase-9 Activation in the Mitochondria," The Journal of Biological Chemistry, Vol. 278, No. 19, 2003, pp. 17408-17420. doi:10.1074/jbc.M300750200

[14] B. Fadeel, S. Orrenius and B. Zhivotovsky, "The Most Unkindest Cut of All: On the Multiple Roles of Mammalian Caspases," Leukemia, Vol. 14, No. 8, 2000, pp. 1514-1525. doi:10.1038/sj.leu.2401871

[15] N. A. Thornberry and Y. Lazebnik, "Caspases: Enemies within," Science, Vol. 281, No. 5381, 1998, pp. 13121316. doi: $10.1126 /$ science. 281.5381 .1312

[16] C. Wongtrakool and J. Roman, "Apoptosis of Mesenchymal Cells during the Pseudoglandular Stage of Lung Development Affects Branching Morphogenesis," EXperimental Lung Research, Vol. 34, No. 8, 2008, pp. 481499. doi:10.1080/01902140802271842

[17] A. Janoff and H. Carp, "Possible Mechanisms of Emphysema in Smokers: Cigarette Smoke Condensate Suppresses Protease Inhibition in Vitro," American Review Respiratory Disease, Vol. 116, No. 1, 1977, pp. 65-72.

[18] A. R. Tabassian, E. S. Nylen, A. E. Giron, R. H. Snider, M. M. Cassidy and K. L. Becker, "Evidence for Cigarette Smoke-Induced Calcitonin Secretion from Lungs of Man and Hamster," Life Sciences, Vol. 42, No. 23, 1988, pp. 2323-2329. doi:10.1016/0024-3205(88)90185-3

[19] J. E. Scott, S. Y. Yang, E. Stanik and J. E. Anderson, "Influence of Strain on [3H]Thymidine Incorporation, Surfactant-Related Phospholipid Synthesis, and Camp Levels in Fetal Type II Alveolar Cells," American Journal of Respiratory Cell and Molecular Biology, Vol. 8, No. 3, 1993, pp. 258-265.

[20] J. J. Batenburg, C. J. Otto-Verberne, A. A. Ten Have-Opbroek and W. Klazinga, "Isolation of Alveolar Type II Cells from Fetal Rat Lung by Differential Adherence in Monolayer Culture," Biochimica et Biophysica Acta, Vol. 960 , No. 3, 1988, pp. 441-453. doi:10.1016/0005-2760(88)90053-7

[21] L. Ott, "An Introduction to Statistical Methods and Data Analysis,” Duxbury Press, Pacific Grove, 1977.
[22] H. Fehrenbach, "Alveolar Epithelial Type II Cell: Defender of the Alveolus Revisited," Respiratory Research, Vol. 2, No. 1, 2001, pp. 33-46. doi:10.1186/rr36

[23] Y. Hoshino, T. Mio, S. Nagai, H. Miki, I. Ito and T. Izumi, "Cytotoxic Effects of Cigarette Smoke Extract on an Alveolar Type II Cell-Derived Cell Line," American Journal of Physiology-Lung Cellular and Molecular Physiology, Vol. 281, No. 2, 2001, pp. L509-L516.

[24] K. Aoshiba, M. Koinuma, N. Yokohori and A. Nagai, "Immunohistochemical Evaluation of Oxidative Stress in Murine Lungs after Cigarette Smoke Exposure," Inhalation Toxicology, Vol. 15, No. 10, 2003, pp. 1029-1038.

[25] W. A. Pryor, "Cigarette Smoke Radicals and the Role of Free Radicals in Chemical Carcinogenicity," Environmental Health Perspectives, Vol. 105, No. S4, 1997, pp. 875-882.

[26] J. A. Ambrose and R. S. Barua, "The Pathophysiology of Cigarette Smoking and Cardiovascular Disease: An Update," Journal of the American College of Cardiology, Vol. 43, No. 10, 2004, pp. 1731-1737. doi:10.1016/j.jacc.2003.12.047

[27] S. Joshi and S. Kotecha, "Lung Growth and Development," Early Human Development, Vol. 83, No. 12, 2007, pp. 789-794. doi:10.1016/j.earlhumdev.2007.09.007

[28] R. J. Rona, M. C. Gulliford and S. Chinn, "Effects of Prematurity and Intrauterine Growth on Respiratory Health and Lung Function in Childhood," British Medical Journal, Vol. 306, No. 6881, 1993, pp. 817-820. doi: $10.1136 / \mathrm{bmj} .306 .6881 .817$

[29] L. A. Creuwels, L. M. van Golde and H. P. Haagsman, "The Pulmonary Surfactant System: Biochemical and Clinical Aspects," Lung, Vol. 175, No. 1, 1997, pp. 1-39. doi:10.1007/PL00007554

[30] M. Sexton and J. R. Hebel, "A Clinical Trial of Change in Maternal Smoking and Its Effect on Birth Weight," Journal of the American Medical Association, Vol. 251, No. 7, 1984, pp. 911-915. doi:10.1001/jama.1984.03340310025013

[31] E. von Mutius, "Environmental Factors Influencing the Development and Progression of Pediatric Asthma," Journal of Allergy and Clinical Immunology, Vol. 109, No. 6, 2002, pp. S525-S532. doi:10.1067/mai.2002.124565

[32] X. Li, R. Shu, G. Filippatos and B. D. Uhal, "Apoptosis in Lung Injury and Remodeling," Journal of Applied Physiology, Vol. 97, No. 4, 2004, pp. 1535-1542. doi:10.1152/japplphysiol.00519.2004

[33] H. I. Dieperink, T. S. Blackwell and L. S. Prince, "Hyperoxia and Apoptosis in Developing Mouse Lung Mesenchyme," Pediatric Research, Vol. 59, No. 2, 2006, pp. 185-190. doi:10.1203/01.pdr.0000196371.85945.3a

[34] Y. J. Tan, B. C. Fielding, P. Y. Goh, S. Shen, T. H. Tan, S. G. Lim and W. Hong, "Overexpression of 7a, a Protein Specifically Encoded by the Severe Acute Respiratory Syndrome Coronavirus, Induces Apoptosis via a CaspaseDependent Pathway," Journal of Virology, Vol. 78, No. 24, 2004, pp. 14043-14047. doi:10.1128/JVI.78.24.14043-14047.2004

[35] F. Drakopanagiotakis, A. Xifteri, V. Polychronopoulos and D. Bouros, "Apoptosis in Lung Injury and Fibrosis," 
European Respiratory Journal, Vol. 32, No. 6, 2008, pp. 1631-1638. doi:10.1183/09031936.00176807

[36] S. Kumar, "Caspase Function in Programmed Cell Death," Cell Death \& Differentiation, Vol. 14, No. 1, 2007, pp. 32-43. doi: $10.1038 /$ sj.cdd.4402060

[37] R. Ganesan, P. R. Mittl, S. Jelakovic and M. G. Grutter, "Extended Substrate Recognition in Caspase-3 Revealed by High Resolution X-Ray Structure Analysis," Journal of Molecular Biology, Vol. 359, No. 5, 2006, pp. 1378-
1388. doi:10.1016/j.jmb.2006.04.051

[38] B. B. Wolf, M. Schuler, F. Echeverri and D. R. Green, "Caspase-3 Is the Primary Activator of Apoptotic DNA Fragmentation via DNA Fragmentation Factor-45/Inhibitor of Caspase-Activated DNase Inactivation," The Journal of Biological Chemistry, Vol. 274, No. 43, 1999, pp. 30651-30656. doi:10.1074/jbc.274.43.30651 